\title{
Transient receptor potential genes, smoking, occupational exposures and cough in adults
}

\author{
Lidwien AM Smit ${ }^{1,2,3^{*}}$, Manolis Kogevinas ${ }^{4,5,6,7}$, Josep M Antó ${ }^{4,5,6,8}$, Emmanuelle Bouzigon ${ }^{9,10,11}$, \\ Juan Ramón González ${ }^{4,5,6}$, Nicole Le Moual ${ }^{1,2}$, Hans Kromhout ${ }^{3}$, Anne-Elie Carsin ${ }^{4,5,6}$, Isabelle Pin 12,13,14, \\ Deborah Jarvis $^{15}$, Roel Vermeulen ${ }^{3}$, Christer Janson ${ }^{16}$, Joachim Heinrich ${ }^{17}$, Ivo Gut ${ }^{18,19}$, Mark Lathrop ${ }^{18}$, \\ Miguel A Valverde ${ }^{20}$, Florence Demenais ${ }^{9,10,11}$ and Francine Kauffmann ${ }^{1,2}$
}

\begin{abstract}
Background: Transient receptor potential (TRP) vanilloid and ankyrin cation channels are activated by various noxious chemicals and may play an important role in the pathogenesis of cough. The aim was to study the influence of single nucleotide polymorphisms (SNPs) in TRP genes and irritant exposures on cough.

Methods: Nocturnal, usual, and chronic cough, smoking, and job history were obtained by questionnaire in 844 asthmatic and 2046 non-asthmatic adults from the Epidemiological study on the Genetics and Environment of Asthma (EGEA) and the European Community Respiratory Health Survey (ECRHS). Occupational exposures to vapors, gases, dusts, and/or fumes were assessed by a job-exposure matrix. Fifty-eight tagging SNPs in TRPV1, TRPV4, and TRPA1 were tested under an additive model.
\end{abstract}

Results: Statistically significant associations of 6 TRPV1 SNPs with cough symptoms were found in non-asthmatics after correction for multiple comparisons. Results were consistent across the eight countries examined. Haplotype-based association analysis confirmed the single SNP analyses for nocturnal cough (7-SNP haplotype: $\mathrm{p}$-global $=4.8 \times 10^{-6}$ ) and usual cough (9-SNP haplotype: p-global $\left.=4.5 \times 10^{-6}\right)$. Cough symptoms were associated with exposure to irritants such as cigarette smoke and occupational exposures $(p<0.05)$. Four polymorphisms in TRPV 1 further increased the risk of cough symptoms from irritant exposures in asthmatics and non-asthmatics (interaction $p<0.05$ ).

Conclusions: TRPV1 SNPs were associated with cough among subjects without asthma from two independent studies in eight European countries. TRPV1 SNPs may enhance susceptibility to cough in current smokers and in subjects with a history of workplace exposures.

Keywords: Asthma, Gene-environment interaction, Irritant exposure, Smoking, TRP channel

\section{Background}

TRPV1, TRPV4, and TRPA1 cation channels are members of the vanilloid (TRPV) and ankyrin (TRPA) subfamily of transient receptor potential channels. These channels are expressed in different cells of the lung, including sensory neurons participating in airway reflex responses, bronchial smooth muscle, and epithelial and endothelial cells $[1,2]$. TRPV1 channels are activated by capsaicin, heat, particulate matter, and various noxious

\footnotetext{
* Correspondence: I.a.smit@uu.nl

${ }^{1}$ INSERM, CESP Centre for research in Epidemiology and Population Health, U1018, Respiratory and environmental epidemiology Team, Villejuif F-94807, France

Full list of author information is available at the end of the article
}

chemicals, and are upregulated in airway nerves and airways smooth muscle of individuals with cough [1-4]. It has recently been shown that the TRPV1 Ile585Val single nucleotide polymorphism (SNP) results in a loss-of-channel function, and that this SNP is associated with a lower risk of cough and wheezing among children with asthma [5]. TRPA1 acts as a receptor for a wide range of irritants and chemicals, including air pollutants and some of the principal components of cigarette smoke [6,7]. Agonists of TRPV1 and TRPA1 channels can elicit a reproducible cough response in humans $[8,9]$, and induce neurogenic inflammatory responses in experimental models $[7,10,11]$. TRPV1 and TRPA1 have been put forward as major targets for novel anti-tussive drugs [12,13].

\section{Biomed Central}


TRPV4 could play a role in the pathogenesis of airway disease through regulation of endothelial and epithelial permeability in the lungs, bronchial smooth muscle cell contractility, and mucociliary transport [14-17]. TRPV4 dysfunction has already been associated to airway diseases: airway epithelial cells from cystic fibrosis patients show a defective regulation of TRPV4 $[18,19]$, and SNPs in the TRPV4 gene have been found to be associated with chronic obstructive pulmonary disease (COPD) [20].

Because of the central role of TRP channels in cough response, we hypothesized that variants in genes encoding TRP channels may be associated with cough symptoms. Moreover, given the critical involvement of TRP channels in irritant sensing, TRP variants may be particularly relevant for irritant-induced cough [21]. Exposures to irritants, for instance in cigarette smoke, or in exposures at work can lead to a spectrum of asthma-related symptoms, including cough [21]. In recent years, studies on asthma and chronic cough symptoms in workers exposed to irritant cleaning products have raised interest in chronic or repeated exposures to relatively low levels of irritants [22-24]. However, little is known about the mechanisms implicated in irritant-induced airway disease.

We aimed to study association of SNPs in candidate genes TRPV1, TRPV4, and TRPA1 with cough symptoms. In addition, we explored whether TRP variants modulate associations between occupational exposures and cough symptoms, or between smoking and cough symptoms. The study was carried out in adults from the French Epidemiological study on the Genetics and Environment of Asthma (EGEA) and from the European Community Respiratory Health Survey (ECRHS).

\section{Methods}

\section{Study population and design}

EGEA is a case-control and a family study of asthma [25]. The population comprises individuals with asthma aged 7-70 who were recruited from six chest clinics in five French cities, population-based control subjects, and relatives of asthmatic probands (either the proband's parents and siblings, or the proband's spouse and children). In the present analysis, only genetically unrelated adults aged 27-70 from the parental generation (adults with asthma and spouse, or the parents of an individual with asthma) were included, as described in detail elsewhere [26].

The methodology of ECRHS has been described elsewhere [27]. Briefly, the ECRHS is a random populationbased multicentre cohort from sixteen centers (eight countries with DNA samples) of subjects aged 20-44 at time of recruitment (1990, ECRHS-I) and then followedup approximately 10 years later (ECRHS-II). In addition to the random sample, a complementary, enriched sample of subjects with asthma symptoms at recruitment but who had not been selected at random to take part in ECRHS-II was also included in the study and follow-up. All asthma cases and a random sample of subjects without asthma were genotyped [28].

In total, 689 subjects from EGEA and 2201 subjects from ECRHS with complete questionnaire and TRP genotyping data were included in the present analysis (844 subjects with asthma, 2046 subjects without asthma). Additional file 1: Figures S1 and S2 present a flow chart of the study population. Ethical approval was obtained for EGEA and for each ECRHS centre from the appropriate institutional ethics committee and written consent was obtained from each participant.

\section{Questionnaire}

Identical questions were used to assess cough symptoms, job history, and smoking in both studies [29]. Nocturnal cough was defined as a positive answer to the question "Have you been woken by an attack of coughing at any time in the last 12 months?". Usual cough was defined as a positive answer to the question "Do you usually cough first thing in the morning in the winter?" or "Do you usually cough during the day, or at night, in the winter?". Chronic cough was defined as usual cough and a positive answer to "Do you cough like this on most days for as much as three months each year?". The role of recent respiratory infections (like a common cold) in cough symptoms was studied by the question "Have you had a respiratory infection in the last 3 weeks?". The definition of (ever) asthma in both studies is given in the Additional File. Smoking was defined as described earlier [29,30], and subjects were categorized into three classes: current smokers, ex smokers and never smokers. Subjects reported their two most recent jobs, which were coded according to international standard classification of occupations (ISCO-88). Jobs were linked to low or high exposure to biological dust, mineral dust, and vapors, gases, or fumes using the ALOHA job-exposure matrix (JEM) [31]. Occupational exposure to vapors, gases, dusts, and/ or fumes (VGDF) was defined as low or high exposure to any VGDF in at least one job. More details are given in the Additional File.

\section{Genotyping}

A preliminary candidate gene study on TRPV1 and TRPV4 was conducted earlier in EGEA [32]. To enable replication, we used genome-wide genotyping of all EGEA and ECRHS subjects from the Gabriel consortium genome-wide association study [28], and we included TRPA1 as an additional candidate gene. All SNPs within the gene region (at least $10 \mathrm{~kb}$ upstream of the $5^{\prime}$ end through $5 \mathrm{~kb}$ downstream of the 3' end according to the HapMap database) were selected from the Illumina Human610 quad array panel [28]. Nineteen SNPs in TRPV1 (located at chromosome 
17p13.3), 10 SNPs in TRPV4 (12q24.1), and 29 SNPs in TRPA1 (8q13) were studied. These SNPs fulfilled the quality control criteria that have been applied to the Gabriel study (see Additional File) [28], and allowed us to capture the majority of common haplotype variations of the three genes (i.e., haplotype with a frequency $\geq 5 \%$ ). Additional Figures E3, E4, and E5 show linkage disequilibrium (LD) between SNPs for the three genes.

\section{Statistical analysis}

Statistical analysis is described in detail in the Additional File. The EGEA and ECRHS study populations were pooled to increase statistical power, and consistency of results was verified by analyzing both studies separately and by performing a random effects meta-analysis of EGEA and the eight ECRHS country-specific samples. The latter allowed to test for heterogeneity across samples. Analyses were conducted in subjects with and without asthma separately, because cough is associated with asthma, and EGEA subjects were recruited through asthmatic patients. The effect of single SNPs on cough was tested under an additive genetic model with the minor allele as risk allele, as was done in previous studies that have shown associations between TRPV SNPs and respiratory outcomes $[5,20]$. Subjects without the given cough symptom were studied as the reference group. Population admixture was taken into account by including informative principal components for within-Europe diversity for EGEA and ECRHS as covariates in the association analysis [28]. Age, smoking, sex, occupational exposure, study and sample (dummy indicators for EGEA, random sample ECRHS, and symptomatic sample of ECRHS) were also incorporated in the logistic model. $\mathrm{P}$-values of association were corrected to address multiple testing $(n=174$ tests, i.e. 58 SNPs $\times 3$ cough outcomes) using the Benjamini-Hochberg method [33]. Haplotype association analyses were assessed using SNPassoc [34] and haplo.stats [35] R packages, and we further used an unbiased sliding window approach to construct successive and adjacent 2- to 9-SNPs haplotypes. To explore whether the effect of occupational exposure or current smoking on cough was modified by TRP genotype we introduced a multiplicative gene-environment interaction term in the model (SNP $\times$ occupational exposure or SNP $\times$ current smoking). The statistical significance of the interaction term was assessed by using a generalized score test which follows a chi-square distribution with 1 degree of freedom.

\section{Results}

Personal characteristics and the prevalence of cough symptoms of the study population are shown in Table 1. Any type of cough was reported by $60.0 \%$ of subjects with asthma, and $33.7 \%$ of subjects without asthma.
Among subjects with asthma, 25.8\% reported both nocturnal cough and usual cough, $22.0 \%$ reported nocturnal cough but no usual cough, and $12.2 \%$ reported usual cough but no nocturnal cough. For subjects without asthma, these prevalence rates were $8.3 \%, 18.0 \%$, and $7.4 \%$, respectively. Women were less often exposed to VGDF than men, and were more often never smokers $(\mathrm{p}<0.01)$. Exposure to VGDF was not associated with asthma (OR 0.99 [0.81-1.21]), and this association did not differ between men and women.

\section{Occupational exposures, smoking and cough symptoms}

In subjects with asthma, female gender was significantly associated with all cough symptoms, and current smoking was associated with usual cough and chronic cough (Table 2). When current smokers were stratified by median cigarette consumption (16 pack-years), the association was only observed for heavy smokers. Occupational exposure to VGDF was significantly associated with nocturnal cough (OR 1.39 [1.04-1.87]) and chronic cough (OR 1.69 [1.18-2.43]). Respiratory infection during the last 3 weeks was only significantly associated with an increased prevalence of nocturnal cough. In subjects without asthma, nocturnal cough was more prevalent among female subjects, and current smoking was associated with all cough symptoms. The association was stronger for heavy smokers but statistically significant also for light smokers. Respiratory infection was positively and significantly associated with nocturnal cough and usual cough. No association between occupational exposure and cough symptoms was found (Table 2). Although the pattern of determinants was similar in both studies, associations with occupation in asthmatics tended to be stronger in EGEA (chronic cough: OR 2.82 [1.39-5.72]) than in ECRHS (OR 1.34 [0.87-2.07])

\section{Association analysis TRP polymorphisms and cough}

In subjects without asthma, 10 TRPV1 SNPs were associated with nocturnal cough $\left(4.3 \times 10^{5} \leq \mathrm{p} \leq 0.044\right)$, 6 TRPV1 SNPs were associated with usual cough $(2.0 \times$ $\left.10^{-5} \leq \mathrm{p} \leq 0.046\right)$, and 4 TRPV1 SNPs were associated with chronic cough $(0.005 \leq \mathrm{p} \leq 0.045)$ (Table 3$)$. After adjustment for multiple testing, 7 associations between TRPV1 SNPs and cough symptoms remained statistically significant (Table 3). All associations between TRPV1 SNPs and cough that were significant in the pooled analysis (after correction for multiple testing) showed the same direction of association in ECRHS and EGEA (Additional file 1: Table S1 and S2). Seven associations were statistically significant in both studies. We estimated a summary OR for these SNPs using a random effects meta-analysis applied to EGEA and the separate ECRHS countries (Figure 1). The OR estimates from the pooled analysis and random effects meta-analysis were 
Table 1 Characteristics of the study population

\begin{tabular}{|c|c|c|c|c|c|c|}
\hline & \multicolumn{3}{|c|}{ Asthma } & \multicolumn{3}{|c|}{ No asthma } \\
\hline & Men & Women & $P$ value & Men & Women & $P$ value \\
\hline $\begin{array}{l}\mathrm{n} \\
\text { Study, n (\%) }\end{array}$ & 368 & 476 & & 1008 & 1038 & \\
\hline EGEA & $107(29.1)$ & $96(20.2)$ & & $248(24.6)$ & $238(22.9)$ & \\
\hline ECRHS & $261(70.9)$ & $380(79.8)$ & & $760(75.4)$ & $800(77.1)$ & \\
\hline $\begin{array}{l}\text { Age, mean (sd) } \\
\text { Smoking habits, n (\%) }\end{array}$ & $44.4(8.3)$ & $42.2(7.4)$ & 0.006 & $44.1(7.7)$ & $43.9(7.5)$ & 0.65 \\
\hline Never smokers & $141(38.3)$ & $232(48.7)$ & 0.004 & $372(36.9)$ & $515(49.6)$ & $<0.001$ \\
\hline Ex smokers & $130(35.3)$ & $125(26.3)$ & & $278(27.6)$ & $237(22.8)$ & \\
\hline Current smokers & $97(26.4)$ & $119(25.0)$ & & $358(35.5)$ & $286(27.6)$ & \\
\hline$\leq 16$ pack-years & $36(9.8)$ & $66(13.9)$ & & $121(12.0)$ & $150(14.5)$ & \\
\hline$>16$ pack-years & 49 (13.3) & $40(8.4)$ & & $188(18.7)$ & $88(8.5)$ & \\
\hline pack-years unknown & $12(3.3)$ & $13(2.7)$ & & $49(4.9)$ & $48(4.6)$ & \\
\hline $\begin{array}{l}\text { Exposure to VGDF, } \mathrm{n}(\%)^{*} \\
\text { Cough symptoms, } \mathrm{n}(\%)\end{array}$ & $182(51.0)$ & $182(39.8)$ & 0.002 & $544(55.0)$ & $361(36.0)$ & $<0.001$ \\
\hline Nocturnal cough & $131(35.7)$ & $272(57.1)$ & $<0.001$ & $226(22.4)$ & $314(30.3)$ & $<0.001$ \\
\hline Usual Cough & $123(33.6)$ & $195(41.4)$ & $<0.001$ & $167(16.6)$ & $152(14.7)$ & 0.23 \\
\hline Chronic cough & $64(17.7)$ & $103(22.1)$ & 0.12 & $73(7.3)$ & $52(5.1)$ & 0.03 \\
\hline Respiratory infection last 3 weeks, n (\%) & $52(14.4)$ & $54(11.5)$ & 0.21 & $87(8.7)$ & $80(7.8)$ & 0.57 \\
\hline
\end{tabular}

*VGDF: vapours, gases, dust, or fumes

Overall, out of 1157 subjects with any type of cough, 550 had nocturnal only (47.5\%), 150 usual cough only (13.0\%), 92 chronic cough (7.9\%), 165 usual and nocturnal (14.3\%) and 200 chronic and nocturnal (17.3\%)

Twenty-eight subjects had missing values for one of the cough variables. Forty-two subjects had missing values for the infection variable

similar. Forest plots showed highly consistent results in the different countries for the association between usual cough and TRPV1 rs17706630 ( $\mathrm{p}$ heterogeneity $=0.932$ ) and rs2277675 ( $\mathrm{p}=0.886)$ and consistency for the association between TRPV1 rs17706630 ( $\mathrm{p}=0.162)$, rs2277675 ( $\mathrm{p}=0.275)$, and rs224498 ( $=0.542)$ and nocturnal cough, whereas heterogeneity was observed for the association between two TRPV1 SNPs and nocturnal cough ( $r$ 161365; $\mathrm{p}=0.048$ and rs150854; $\mathrm{p}=0.040$ ). The associations between TRPV1 SNPs and cough symptoms did not differ between men and women ( $\mathrm{p}$ for interaction $>0.05$ for all SNPs). Further, excluding those with FEV1 $<80 \%$ predicted did not change the results.

In subjects with asthma, two TRPV1 SNPs were associated with usual cough, but the associations did not remain significant after correction for multiple testing (Table 3). Associations between SNPs in TRPV4 and TRPA1 and cough symptoms in subjects with or without asthma were also not significant after adjusting for multiple testing (Additional file 1: Tables S3 and S4).

Table 2 Determinants of nocturnal cough, usual cough, and chronic cough in 844 adults with asthma and in 2046 adults without asthma

\begin{tabular}{|c|c|c|c|c|c|c|}
\hline & \multicolumn{3}{|c|}{ Subjects with asthma } & \multicolumn{3}{|c|}{ Subjects without asthma } \\
\hline & Nocturnal cough & Usual cough & Chronic cough & Nocturnal cough & Usual cough & Chronic cough \\
\hline Female sex & $2.85(2.10-3.86)$ & $1.42(1.05-1.93)$ & $1.49(1.02-2.17)$ & $1.67(1.35-2.07)$ & $0.95(0.73-1.23)$ & $0.78(0.53-1.16)$ \\
\hline Exposure to VGDF* & $1.39(1.04-1.87)$ & $1.29(0.96-1.73)$ & $1.69(1.18-2.43)$ & $1.09(0.88-1.35)$ & $0.98(0.75-1.27)$ & $1.05(0.70-1.56)$ \\
\hline Age, per 10 y & $1.17(0.96-1.42)$ & $1.10(0.90-1.34)$ & $1.16(0.90-1.48)$ & $1.04(0.91-1.21)$ & $1.10(0.91-1.32)$ & $1.16(0.88-1.54)$ \\
\hline Ex smoker vs. never smoker & $0.89(0.62-1.26)$ & $0.86(0.60-1.24)$ & $0.65(0.40-1.05)$ & $1.11(0.85-1.46)$ & $0.94(0.64-1.37)$ & $1.07(0.57-2.01)$ \\
\hline Current smoker vs. never smoker & $1.15(0.80-1.66)$ & $2.04(1.43-2.91)$ & $2.12(1.40-3.21)$ & $1.68(1.32-2.14)$ & $3.37(2.53-4.49)$ & $4.26(2.67-6.79)$ \\
\hline$\leq 16$ pack-years vs. never smokert & $1.03(0.64-1.64)$ & $1.08(0.67-1.74)$ & $1.13(0.63-2.02)$ & $1.28(0.93-1.76)$ & $2.18(1.49-3.19)$ & $2.31(1.24-4.33)$ \\
\hline$>16$ pack-years vs. never smokert & $1.44(0.87-2.39)$ & $4.45(2.66-7.45)$ & $3.71(2.20-6.27)$ & $2.34(1.71-3.20)$ & $5.18(3.66-7.34)$ & $6.43(3.79-10.92)$ \\
\hline Respiratory infection last 3 weeks & $1.84(1.18-2.87)$ & $1.17(0.76-1.82)$ & $1.13(0.68-1.90)$ & $2.45(1.74-3.44)$ & $1.51(1.00-2.29)$ & $1.54(0.84-2.83)$ \\
\hline
\end{tabular}

Multivariate GEE model, adjusted for all variables in the table, principal components for within-Europe diversity, sample, and study; results are presented as OR (95\% Cl). Bold type indicates $P<0.05$

*VGDF: vapours, gases, dust, or fumes

† in models without current smoker vs. never smoker. Coefficients for all other variables were basically similar (e.g.OR were for nocturnal cough $2.57,1.27,1.15$, 0.89 and 1.67, 1.06, 1.01 and 1.13 for sex, VGDF, age and ex-smoker in subjects with and without asthma respectively) 
Table 3 Association of TRPV1 SNPs with nocturnal cough, usual cough, and chronic cough under an additive model in 844 adults with asthma and 2046 adults without asthma

\begin{tabular}{|c|c|c|c|c|c|c|c|c|c|}
\hline \multirow[b]{2}{*}{ SNP } & \multirow[b]{2}{*}{ Region } & \multirow[b]{2}{*}{ Alleles $^{\dagger}$} & \multirow[b]{2}{*}{ MAF } & \multicolumn{3}{|c|}{ Subjects with asthma } & \multicolumn{3}{|c|}{ Subjects without asthma } \\
\hline & & & & Nocturnal cough & Usual cough & Chronic cough & Nocturnal cough & Usual cough & Chronic cough \\
\hline rs4790522 & $3^{\prime} U T R$ & $C / A$ & 0.41 & $0.97(0.78-1.20)$ & $1.35(1.09-1.67)$ & $1.19(0.92-1.55)$ & $1.20(1.03-1.39)$ & $1.31(1.10-1.57)$ & $1.01(0.77-1.31)$ \\
\hline rs16953163 & intron & $A / G$ & 0.20 & $0.95(0.73-1.23)$ & $0.83(0.64-1.09)$ & $0.81(0.58-1.12)$ & $1.10(0.92-1.30)$ & $1.08(0.88-1.34)$ & $1.15(0.84-1.57)$ \\
\hline rs224546 & intron & $\mathrm{T} / \mathrm{C}$ & 0.42 & $0.96(0.77-1.18)$ & $1.27(1.03-1.58)$ & $1.07(0.83-1.39)$ & $1.16(1.00-1.35)$ & $1.09(0.91-1.30)$ & $0.89(0.68-1.15)$ \\
\hline rs11655540 & intron & $\mathrm{T} / \mathrm{G}$ & 0.35 & $1.03(0.83-1.28)$ & $0.89(0.71-1.10)$ & $1.03(0.79-1.34)$ & $0.77(0.66-0.90){ }^{*}$ & $0.85(0.70-1.03)$ & $1.09(0.83-1.43)$ \\
\hline rs161364 & intron & $\mathrm{C} / \mathrm{T}$ & 0.28 & $0.93(0.73-1.17)$ & $1.12(0.89-1.42)$ & $1.11(0.84-1.47)$ & $1.09(0.93-1.29)$ & $1.22(1.01-1.49)$ & $1.13(0.84-1.52)$ \\
\hline rs8065080 & |le585Val & $\mathrm{T} / \mathrm{C}$ & 0.39 & $0.94(0.76-1.15)$ & $0.94(0.76-1.15)$ & $0.91(0.70-1.18)$ & $1.15(0.99-1.33)$ & $0.92(0.77-1.10)$ & $0.90(0.69-1.19)$ \\
\hline rs161365 & intron & $C / T$ & 0.32 & $1.11(0.89-1.39)$ & $0.91(0.73-1.15)$ & $0.86(0.66-1.13)$ & $0.72(0.62-0.85)^{*^{\ddagger}}$ & $0.85(0.70-1.05)$ & $1.02(0.76-1.38)$ \\
\hline rs150908 & intron & $\mathrm{G} / \mathrm{A}$ & 0.44 & $0.87(0.71-1.07)$ & $1.00(0.81-1.23)$ & $0.94(0.73-1.20)$ & $1.10(0.95-1.28)$ & $1.23(1.03-1.48)$ & $1.21(0.93-1.58)$ \\
\hline rs224534 & Thr469lle & $\mathrm{G} / \mathrm{A}$ & 0.35 & $0.86(0.69-1.06)$ & $0.90(0.73-1.11)$ & $0.97(0.76-1.25)$ & $1.01(0.87-1.18)$ & $1.14(0.96-1.36)$ & $1.24(0.96-1.61)$ \\
\hline rs17706630 & intron & $G / A$ & 0.27 & $1.02(0.81-1.30)$ & $0.95(0.75-1.21)$ & $1.00(0.76-1.32)$ & $0.71(0.59-0.84)^{*^{\ddagger}}$ & $0.73(0.59-0.92)^{\ddagger}$ & $0.71(0.50-0.99)$ \\
\hline rs 222748 & His167His & $G / A$ & 0.11 & $1.00(0.72-1.40)$ & $0.92(0.66-1.28)$ & $1.20(0.82-1.76)$ & $0.97(0.76-1.23)$ & $1.18(0.89-1.56)$ & $1.32(0.88-1.97)$ \\
\hline rs150846 & intron & $G / A$ & 0.36 & $1.12(0.91-1.38)$ & $1.08(0.87-1.33)$ & $1.11(0.85-1.44)$ & $1.22(1.05-1.41)$ & $1.18(0.99-1.42)$ & $1.25(0.96-1.62)$ \\
\hline rs 2277675 & $5^{\prime} U T R$ & $\mathrm{~T} / \mathrm{C}$ & 0.28 & $1.17(0.93-1.46)$ & $0.97(0.77-1.21)$ & $1.04(0.79-1.35)$ & $0.73(0.62-0.86)^{*^{\ddagger}}$ & $0.64(0.52-0.80)^{* \neq}$ & $0.64(0.46-0.90)$ \\
\hline rs161381 & 5'UTR & $\mathrm{G} / \mathrm{T}$ & 0.15 & $1.05(0.79-1.39)$ & $1.21(0.91-1.61)$ & $1.06(0.75-1.50)$ & $1.20(0.98-1.47)$ & $1.19(0.93-1.51)$ & $1.07(0.75-1.55)$ \\
\hline rs222738 & S'UTR $^{\prime}$ & $C / T$ & 0.09 & $0.99(0.69-1.40)$ & $0.93(0.64-1.33)$ & $1.14(0.73-1.77)$ & $0.84(0.65-1.09)$ & $1.12(0.82-1.51)$ & 1.37 (0.89-2.09) \\
\hline rs17707155 & 5'UTR & $\mathrm{C} / \mathrm{T}$ & 0.28 & $0.91(0.73-1.14)$ & $0.97(0.77-1.21)$ & $0.99(0.75-1.31)$ & $1.23(1.05-1.43)$ & $1.01(0.83-1.22)$ & $1.05(0.78-1.40)$ \\
\hline rs222741 & $5^{\prime}$ & $\mathrm{A} / \mathrm{G}$ & 0.24 & $1.07(0.85-1.34)$ & $1.15(0.90-1.46)$ & $1.11(0.83-1.50)$ & $1.10(0.93-1.30)$ & $1.23(1.01-1.51)$ & $1.40(1.04-1.88)$ \\
\hline rs150854 & $5^{\prime}$ & $\mathrm{T} / \mathrm{G}$ & 0.46 & $1.12(0.91-1.37)$ & $0.96(0.78-1.18)$ & $0.94(0.73-1.21)$ & $0.74(0.64-0.86)^{*^{\ddagger}}$ & $0.84(0.70-1.00)$ & $0.76(0.57-1.00)$ \\
\hline rs224498 & $5^{\prime}$ & $\mathrm{T} / \mathrm{G}$ & 0.39 & $0.93(0.76-1.15)$ & $1.16(0.94-1.43)$ & $0.99(0.76-1.27)$ & $1.32(1.14-1.53)^{*^{\ddagger}}$ & $1.11(0.92-1.33)$ & $1.00(0.76-1.31)$ \\
\hline
\end{tabular}

Results are presented as $\mathrm{OR}(95 \% \mathrm{Cl})$ adjusted for age, sex, smoking habits, occupational exposure, principal components for within-Europe diversity, study, and sample

Bold type indicates $P<0.05,{ }^{*} P$-value adjusted for multiple comparisons $<0.05 .{ }^{+}$Major/minor allele. MAF, minor allele frequency. ${ }^{\ddagger} P<0.05$, both in EGEA and ECRHS 


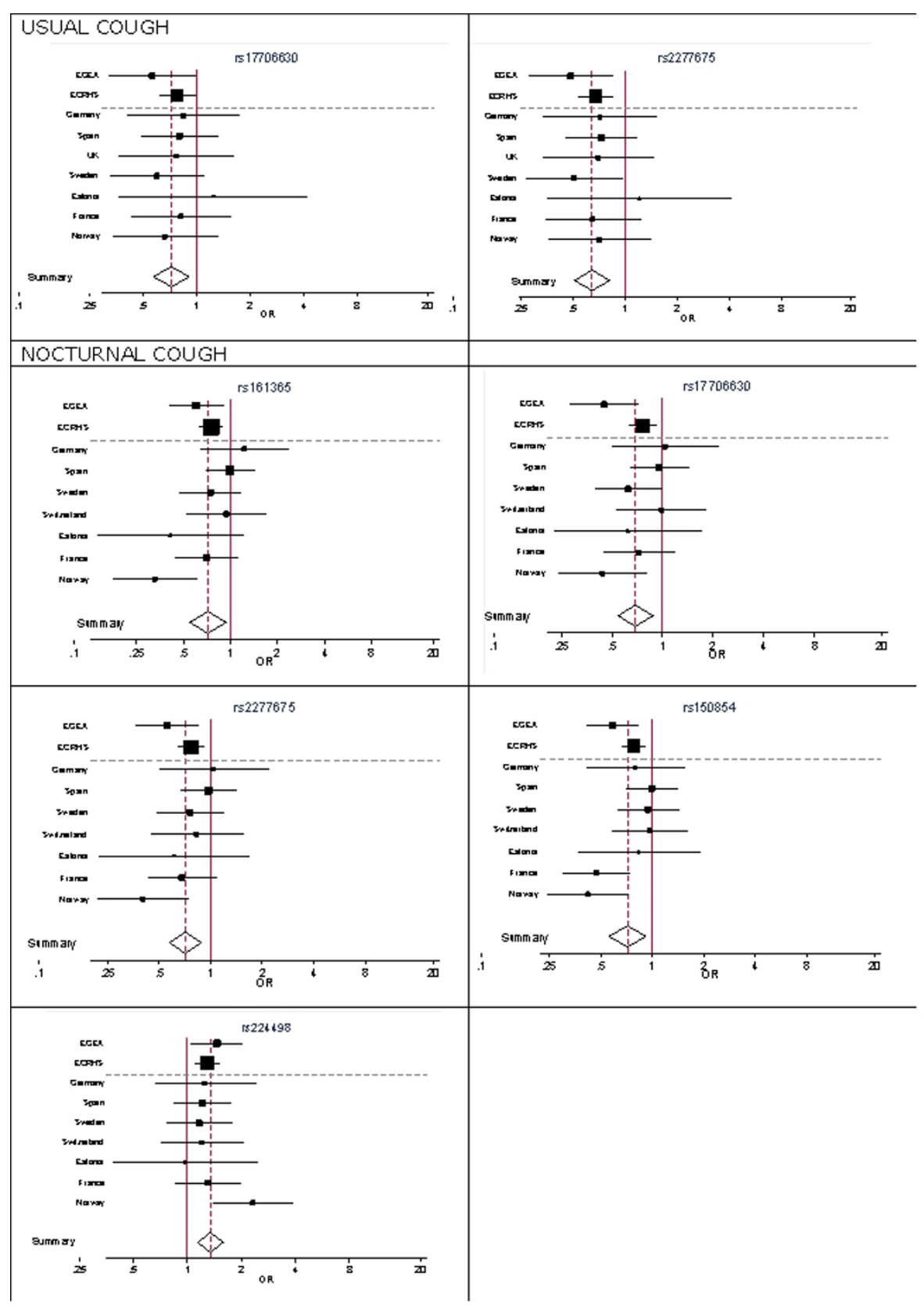

Figure 1 Forest plots of odds ratios (OR) for SNPs associated with nocturnal or usual cough in both EGEA and ECRHS, according to study and country (ECRHS). Summary ORs were calculated using a random effects meta-analysis applied to EGEA and the separate ECRHS countries. Summary ORs $(95 \% \mathrm{Cl})$ for the association between rs17706630 and rs2277675 and usual cough were $0.72(0.57-0.91)$ and 0.64 (0.510.81), respectively. Summary ORs $(95 \% \mathrm{Cl})$ for the association between rs161365, rs17706630, rs2277675, rs150854, and rs224498 and nocturnal cough were $0.72(0.55-0.94), 0.69(0.54-0.88), 0.71(0.58-0.88), 0.72(0.56-0.92)$, and $1.34(1.14-1.58)$, respectively. ORs for associations with usual cough could not be estimated for Switzerland, and ORs for nocturnal cough could not be estimated for the United Kingdom (UK)

Haplotype-based association analysis TRPV1 and cough Pairwise LD $\left(\mathrm{r}^{2}\right)$ between the TRPV1 SNPs that were associated with cough symptoms was $\leq 0.72$ (Additional file 1: Figure S3). We performed a sliding window approach to construct haplotypes across combinations of successive SNPs that were associated with nocturnal cough and usual cough in subjects without asthma. The best result for nocturnal cough was a 7-SNP haplotype comprising adjacent SNPs from rs8065080 to rs150846 $\left(\mathrm{p}\right.$-global $=4.8 \times 10^{-6}$, Additional file 1: Figure S6). For 
usual cough, a 9-SNP haplotype comprising adjacent SNPs from rs17706630 to rs150854 showed the most significant association ( $\mathrm{p}$-global $=4.5 \times 10^{-6}$, Additional file 1: Figure S7). Tables 4 and 5 show association analysis of specific TRPV1 haplotypes and nocturnal cough and usual cough, respectively. The haplotype analysis supported the results obtained by single SNP analysis.

\section{Gene-environment interactions between TRPV1}

\section{polymorphisms and occupational exposure or smoking}

We explored whether the effect of occupational exposure or current smoking on cough was enhanced by SNPs in TRPV1 because consistent main effects on cough symptoms were observed for this gene. In subjects without asthma, three TRPV1 SNPs appeared to modify the association between current smoking and cough symptoms $\left(9.0 \times 10^{-4} \leq \mathrm{p}\right.$ interaction $\leq 0.030$; Additional file 1: Table S5). In subjects with asthma, the association between occupational exposure and usual cough and chronic cough appeared to be modified by TRPV1 rs224498. Positive and significant associations between occupational exposure and cough were observed among TT subjects (OR 1.82 [1.11-2.99] for usual cough; OR 2.58 [1.39-4.79] for chronic cough), whereas ORs were close to unity and not statistically significant among GT subjects and GG subjects ( $\mathrm{p}$ interaction $=0.006$ for usual cough and $\mathrm{p}=$ 0.025 for chronic cough).

\section{Discussion}

The present study showed significant associations between TRPV1 SNPs and cough symptoms among subjects without asthma from two independent European studies. Although we carried out a pooled analysis to increase the power of detecting associations of SNPs with cough symptoms, we verified that the results were similar in the EGEA and ECRHS studies, and reached the 5\%

\begin{tabular}{|c|c|c|c|}
\hline Haplotype & Haplotype frequency & OR $(95 \% \mathrm{Cl})$ & $P$ value \\
\hline TTGGAGG & 0.227 & 1.00 (reference) & \\
\hline CCAAGGG & 0.131 & $1.26(0.97-1.64)$ & 0.085 \\
\hline CCGGGGA & 0.120 & $1.54(1.18-2.02)$ & $0.001^{*}$ \\
\hline TCAAGGG & 0.090 & $1.40(1.04-1.90)$ & 0.027 \\
\hline TCAGGGA & 0.087 & $1.55(1.14-2.10)$ & $0.004^{*}$ \\
\hline CCGGGGG & 0.079 & $1.51(1.10-2.05)$ & 0.010 \\
\hline TCAAGAA & 0.061 & $1.53(1.08-2.16)$ & 0.016 \\
\hline Rare haplotypes & 0.205 & $1.19(0.93-1.53)$ & 0.161 \\
\hline
\end{tabular}

Haplotypes are a combination of 7 adjacent SNPs: rs8065080 T/C - rs161365 C/T - rs $150908 \mathrm{G} / \mathrm{A}$ - rs $224534 \mathrm{G} / \mathrm{A}$ - rs $17706630 \mathrm{G} / \mathrm{A}$ - rs222748 G/A rs $150846 \mathrm{G} / \mathrm{A}$. OR and $95 \% \mathrm{Cl}$ are adjusted for age, sex, smoking habits, occupational exposure, principal components for within-Europe diversity, study, and sample. *Significant after Bonferroni correction $(0.05 / 7=0.007)$
Table 5 Haplotype-based association analysis of TRPV1 haplotypes and usual cough in 2046 subjects without asthma

\begin{tabular}{lccc}
\hline Haplotype & Haplotype frequency & OR $(\mathbf{9 5} \% \mathbf{C l})$ & $\boldsymbol{P}$ value \\
\hline AGGCGCCAG & 0.224 & 1.00 (reference) & \\
GGGTGCTAT & 0.158 & $1.25(0.92-1.71)$ & 0.152 \\
GGGTGCCAG & 0.140 & $1.53(1.13-1.08)$ & $0.006^{*}$ \\
GGATTCCGT & 0.123 & $1.54(1.11-2.14)$ & 0.010 \\
GGATGCTAT & 0.099 & $1.24(0.87-1.77)$ & 0.241 \\
GAATGTCGT & 0.070 & $1.60(1.09-2.35)$ & 0.016 \\
Rare haplotypes & 0.186 & $1.15(0.84-1.58)$ & 0.382 \\
\hline
\end{tabular}

Haplotypes are a combination of 9 adjacent SNPs: rs17706630 G/A - rs222748 $\mathrm{G} / \mathrm{A}$ - rs150846 G/A - rs2277675 T/C - rs161381 G/T - rs222738 C/T rs $17707155 \mathrm{C} / \mathrm{T}-\mathrm{rs} 222741 \mathrm{~A} / \mathrm{G}-\mathrm{rs} 150854 \mathrm{~T} / \mathrm{G}$. OR and $95 \% \mathrm{Cl}$ are adjusted for age, sex, smoking habits, occupational exposure, principal components for within-Europe diversity, study, and sample. *Significant after Bonferroni correction $(0.05 / 6=0.0083)$

significance level for five SNPs in each study. Randomeffects meta-analysis of these SNPs showed similar estimates of the summary ORs with those obtained from the pooled analysis and no evidence of heterogeneity across the different studies and countries involved for three of these SNPs. Haplotype-based association analysis confirmed the single SNP analyses, and global p-values for association between TRPV1 haplotypes and cough were highly significant $\left(\mathrm{p}<5 \times 10^{-6}\right)$.

The functional relevance of these TRPV1 SNPs, or variants not genotyped but in high LD with one of these SNPs, is so far unknown. TRPV1 variants could result in either activity or expression changes of TRPV1 channels in airway nerves or airways smooth muscle, influencing sensitivity for TRPV1-activating agents among carriers of such a variant. In a recent report, Cantero-Recasens et al. [5] have shown that a isoleucine-to-valine mutation at position 585 of the TRPV1 protein results in a $20-30 \%$ loss of channel function, and that the corresponding TRPV1 I585V (rs8065080) SNP is associated with a significantly lower risk of wheeze and cough in children with asthma. The structural explanation for the altered activity of TRPV1 $585 \mathrm{~V}$ is not known at present, and channel activity of other TRPV1 variants needs to be evaluated. In the present analysis, TRPV1 I585V was also associated with a lower risk of nocturnal cough in EGEA adults with asthma (OR 0.62 [0.40-0.96], $\mathrm{p}=0.03$ ), but the association was not statistically significant in the pooled analysis. We did not find evidence of an association between common TRPA1 or TRPV4 variants and cough. The lack of association between SNPs in TRPA1 and cough was especially surprising, since many ubiquitous environmental irritants have been shown to activate TRPA1 receptors to cause cough $[13,21]$. The significant associations of TRPV1 variants with cough imply that our study population was large enough to reveal moderately increased or decreased risk estimates, suggesting 
that the lack of association cannot be attributed to a lack of power in our study. Our study was the first to explore associations of TRPA1 variants and respiratory outcomes. We cannot exclude the possibility that other respiratory outcomes such as bronchial hyperresponsiveness or more specific (irritant-induced) cough phenotypes are associated with these variants. Moreover, other unidentified rare genetic variants in TRPA1 or TRPV4 may play a role.

TRPV1 and TRPA1 are prime candidate genes for gene-environment interactions with exposures to a wide range of irritants and chemicals that may be encountered in the workplace, but also in air pollution and in cigarette smoke. The present findings seem to support this hypothesis by suggesting that interactions between TRPV1 SNPs and occupational exposures and smoking may modify the risk of cough symptoms. However, given the large number of tests performed, our findings on gene-environment interaction should be taken cautiously. Our observation that TRPV1 variants interact with irritants that may be present in occupational exposures or cigarette smoke to increase the risk of cough symptoms needs replication in other epidemiological or functional studies.

Chronic cough is one of the most frequent reasons for consultation with a primary care or respiratory physician, and may cause important adverse psychosocial and physical effects on patients' quality of life [36]. There is an unmet need for effective anti-tussive drugs for cough patients [37]. TRPV1 is being pursued as one of the potential therapeutic targets, and TRPV1 antagonists are being developed [13,37]. The results of our genetic association study seem to support the hypothesis that modulation of TRPV1 channel activity may provide therapeutic benefit in cough. However, some TRPV1 antagonists cause significant side effects on body temperature, which has necessitated the withdrawal of these compounds from clinical trials [13]. To date, both the scientific community and pharmaceutical industry are centered in the finding of a TRPV1 modulator to treat pain, without affecting temperature homeostasis. Potentially, the finding of such a modulator could be used as an antitussive agent.

Although cough is frequently associated with asthma [29], it has also been shown that in a general population, chronic cough may present as an independent symptom [38]. Further, recent observations of chronic cough in subjects without obvious respiratory disease such as asthma, have suggested the existence of a distinct clinical entity, the cough hypersensitivity syndrome $[39,40]$. The mechanisms of idiopathic cough are unclear, but the enhanced cough reflex in patients may result from increased sensitivity of cough receptors such as TRPV1 [39]. In non-asthmatic chronic cough patients, increased expression of TRPV1 was shown [3]. In our study, TRPV1 polymorphisms were associated with cough, but only in subjects without asthma. It is worth noting that associations with cough in those without asthma hold for those without airflow limitation, i.e. in subjects with cough independent of asthma or COPD. Thus, it could be hypothesized that genetic variation in TRPV1 increases the risk of an enhanced cough reflex among subjects without asthma. In asthmatics, the situation may be more complex, and the (modest) effect of genetic variation on TRPV1 channel activity may be obscured by the influence of other mechanims such as airway inflammation. For example, in asthma patients, chronic cough is associated with poor control of asthma and the use of inhaled corticosteroids [41]. To further elucidate the difference between subjects with and without asthma, studies with more specific cough phenotypes would be useful. Future replication studies could assess whether TRPV1 polymorphisms may be associated with greater cough sensitivity to inhaled capsaicin in cough patients (with and without asthma). Such a study could also include TRPV1 gene expression analysis before and after capsaicin challenge.

Women have greater cough sensitivity to inhaled capsaicin than men, as was shown in cough patients and healthy volunteers $[42,43]$. The reason for the greater sensitivity among women is unknown, and it is unlikely that smaller airway size and sex hormones explain these differences $[42,43]$. In the present study, cough prevalence was also strongly associated with female sex, in particular among asthmatics, but the associations between TRPV1 SNPs and cough symptoms were not different for men and women.

We used occupational exposure to vapors, gases, dust, and/or fumes as a proxy of work-related irritant exposure. VGDF comprises a wide variety of exposures to occupational agents, including irritants that may induce cough by activation of TRP receptors. One can assume that misclassification of irritant exposures by VGDF is of a non-differential nature, resulting in estimated measures of association that are biased toward the null, and a negative impact on the power to observe gene-environment interactions between VGDF exposure and TRP variants. Asthma was unrelated to VGDF exposure, a result consistent with previous results [24]. However, exposure to VGDF may modify the expression of asthma by increasing cough, which appears to be long-lasting since not all subjects were currently exposed. Long-term respiratory effects of occupational irritant exposures have been shown before, for example among women formerly employed in domestic cleaning [22].

\section{Conclusion}

TRPV1 SNPs were associated with nocturnal, usual, and chronic cough in subjects without asthma from two independent studies in eight European countries. Irritant 
exposures such as cigarette smoking and occupational exposures were associated with cough symptoms. Exploratory findings on gene-environment interaction suggested that these associations may be enhanced by TRPV1 SNPs.

\section{ECRHS, list of Principal Investigators and Senior Scientific Team (Members of the ECRHS Steering Committee in italics)}

France: Paris (F Neukirch, B Leynaert, R Liard, M Zureik), Grenoble (I Pin, J Ferran-Quentin). Germany: Erfurt (J Heinrich, $M$ Wjst, C Frye, I Meyer). Norway: Bergen (A. Gulsvik, E. Omenaas, C. Svanes, B. Laerum). Spain: Barcelona (JM Antó, J Sunyer, M Kogevinas, JP Zock, × Basagana, F Burgos), Huelva (J Maldonado, A Pereira, JL Sanchez), Albacete (J Martinez-Moratalla Rovira, E Almar), Galdakao (N Muniozguren, I Urritia), Oviedo (F Payo). Sweden: Uppsala (C Janson, G Boman, D Norback, M Gunnbjornsdottir), Umea (E Norrman, M Soderberg, K Franklin, B Lundback, B Forsberg, L Nystrom). Switzerland: Basel (N Künzli, B Dibbert, M Hazenkamp, M Brutsche, U Ackermann-Liebrich). United Kingdom: P Burney, S Chinn, D Jarvis, Norwich (D Jarvis, B Harrison), Ipswich (D Jarvis, R Hall, D Seaton).

\section{Additional material}

Additional file 1: Additional Methods, Tables and Figures

\begin{abstract}
Abbreviations
Cl: Confidence interval; COPD: Chronic obstructive pulmonary disease; ECRHS: European Community Respiratory Health Survey; EGEA: Epidemiological study on the Genetics and Environment of Asthma; JEM: Job-exposure matrix; LD: Linkage disequilibrium; OR: Odds ratio; SNP: Single nucleotide polymorphism; TRPA: Transient receptor potential ankyrin; TRPV: Transient receptor potential vanilloid; VGDF: Vapors: gases: dusts: and/or fumes.
\end{abstract}

\section{Acknowledgements}

The EGEA study was funded by INSERM, grants from the French Agency for Environmental and Occupational Health Safety (grant AFSSET-APR-SE-2004), the French National Agency for Research (grants ANR 05-SEST-020-02/05-997, ANR 06-CEBS and ANR 10-PRSP) and Merck Sharp \& Dohme (MSD). Regarding ECRHS II, the coordination was supported by the European Commission, as part of their Quality of Life programme. The following bodies funded the local studies in ECRHS II in this article. Albacete - Fondo de Investigaciones Santarias (grant code: 97/0035-01, 13 99/0034-01 and 99/ 0034-02), Hospital Universitario de Albacete, Consejeria de Sanidad.Antwerp FWO (Fund for Scientific Research)- Flanders Belgium (grant code: G.0402.00), University of Antwerp, Flemish Health Ministry.Barcelona - Fondo de Investigaciones Sanitarias (grant code: 99/0034-01 and 99/0034-02), Red Respira (RTIC 03/11 ISC IF). Ciber of Epidemiology and Public Health has been established and founded by Instituto de Salud Carlosill.Basel - Swiss National Science Foundation, Swiss Federal Office for Education \& Science, Swiss National Accident Insurance Fund (SUVA).Bergen - Norwegian Research Council; Norwegian Asthma \& Allergy Association (NAAF); Glaxo Wellcome AS, Norway Research Fund.Bordeaux - Institut Pneumologique d'Aquitaine. Erfurt - GSF-National Research Centre for Environment \& Health, Deutsche Forschungsgemeinschaft (DFG) (grant code FR 1526/1-1).Galdakao - Basque Health Department.Gothenburg - Swedish Heart Lung Foundation,
Swedish Foundation for Health Care Sciences \& Allergy Research, Swedish Asthma \& Allergy Foundation, Swedish Cancer \& Allergy Foundation. Grenoble - Programme Hospitalier de Recherche Clinique-DRC de Grenoble 2000 no. 2610, Ministry of Health, Directionde la Recherche Clinique, Ministere de l'Emploi et de la Solidarite, Direction Generale de la Sante, CHU de Grenoble, Comite des Maladies Respiratoires de l'Isere. Hamburg - GSFNational Research Centre for Environment \& Health, Deutsche Forschungsgemeinschaft (DFG) (grant code MA 711/4-1). Ipswich and Norwich - Asthma UK (formerly National Asthma Campaign) (UK). Huelva Fondo de Investigaciones Sanitarias (FIS) (grant code: 97/0035-01, 99/003401 and 99/003402). Montpellier - Programme Hospitalier de Recherche Clinique-DRC de Grenoble 2000 no. 2610, Ministry of Health, Direction de la Recherche Clinique, CHU de Grenoble, Ministère de l'Emploi et de la Solidarité, Direction Générale de la Santé, Aventis (France), Direction Régionale des Affaires Sanitaires et Sociales Languedoc-Roussillon. Oviedo Fondo de Investigaciones Santarias (FIS) (grant code: 97/0035-01, 99/0034-01 and 99/0034-02). Paris - Ministère de l'Emploi et de la Solidarite, Direction Générale de la Santé, UCBPharma (France), Aventis (France), Glaxo France, Programme Hospitalier de Recherche Clinique-DRC de Grenoble 2000 no. 2610, Ministry of Health, Direction de la Recherche Clinique, CHU de Grenoble. Tartu - Estonian Science Foundation.Umea - Swedish Heart Lung Foundation, Swedish Foundation for Health Care Sciences \& Allergy Research, Swedish Asthma \& Allergy Foundation, Swedish Cancer \& Allergy Foundation. Uppsala - Swedish Heart Lung Foundation, Swedish Foundation for Health Care Sciences \& Allergy Research, Swedish Asthma \& Allergy Foundation, Swedish Cancer \& Allergy Foundation. Further, research has been funded by GABRIEL, a multidisciplinary study to identify the genetic and environmental causes of asthma in the European Community (contract n 01896 under the Integrated Program LSH-2004-1.2.5-1 Post genomic approaches to understand the molecular bias of asthma aiming at a preventive or therapeutic control), by the Netherlands Organisation for Scientific Research (NWO)/French Ministry of foreign and European affairs Van Gogh program for French-Dutch cooperation and by CIBERESP, which has been established and founded by Instituto de Salud Carlos III (ISC III), Spain. M.A. Valverde is the recipient of an ICREA Academia award and has received support from the Spanish Ministry of Science and Innovation, FEDER Funds and Plan E (grant SAF2009-09848), Generalitat de Catalunya (grant 2009SGR-1369), ISCIII-RETIC RD06/02 and Marato TV3 (080430). L.A.M. Smit was supported by a European Academy of Allergology and Clinical Immunology-Global Allergy and Asthma European Network (EAACI-GA ${ }^{2}$ LEN) exchange fellowship award.

\section{Author details}

${ }^{1}$ INSERM, CESP Centre for research in Epidemiology and Population Health, U1018, Respiratory and environmental epidemiology Team, Villejuif F-94807, France. ${ }^{2}$ Université Paris Sud 11, UMRS 1018, Villejuif F-94807, France. ${ }^{3}$ Division of Environmental Epidemiology, Institute for Risk Assessment Sciences, PO Box 80178, 3508 TD Utrecht, The Netherlands. ${ }^{4}$ Centre for Research in Environmental Epidemiology (CREAL), Barcelona, Spain. ${ }^{5}$ Municipal Institute of Medical Research (IMIM-Hospital del Mar), Barcelona, Spain. ${ }^{6}$ CIBER Epidemiologia y Salud Pública (CIBERESP), Barcelona, Spain. ${ }^{7}$ National School of Public Health, Athens, Greece. ${ }^{8}$ Department of Experimental and Health Sciences, Universitat Pompeu Fabra Barcelona, Spain. ${ }^{9}$ INSERM, U946, F-75010, Paris, France. ${ }^{10}$ Université Paris Diderot, Sorbonne Paris Cité, Institut Universitaire d'Hématologie, Paris F-75010, France. ${ }^{11}$ Fondation Jean Dausset-Centre d'Etude du Polymorphisme Humain (CEPH), Paris F-75010, France. ${ }^{12}$ INSERM, U823, Grenoble, France. ${ }^{13}$ Université Joseph Fourier-Grenoble 1, Grenoble, France. ${ }^{14}$ Centre Hospitalier Universitaire de Grenoble, Grenoble, France. ${ }^{15}$ Respiratory Epidemiology and Public Health Group, National Heart and Lung Institute, Imperial College, London, UK. ${ }^{16}$ Department of Medical Sciences: Respiratory Medicine and Allergology, Uppsala University, Uppsala, Sweden. ${ }^{17}$ Institute of Epidemiology, Helmholtz Centre, Munich, Germany. ${ }^{18} \mathrm{Commissariat} \mathrm{à}$ l'Energie Atomique, Institut de Génomique, Centre National de Génotypage (CNG), Evry, France. ${ }^{19}$ Currently Centro Nacional de Analisis Genomico, Barcelona, Spain. ${ }^{20}$ Laboratory of Molecular Physiology and Channelopathies, Universitat Pompeu, Fabra, Barcelona, Spain.

\section{Authors' contributions}

LAMS, JMA, MAV, and FK were involved in the conception, hypotheses delineation, and design of the study. All the above authors and also EB, JRG, 
NLM, HK, AEC, IP, DJ, RV, CJ, JH, IG and ML participated in the acquisition of the data or the analysis and interpretation of such information. LAMS, MK and FK wrote the article. All authors reviewed and commented on the paper and JMA, JRG, AEC, RV, JH, EB, FD and MAV had substantial involvement in its revision prior to submission. All authors read and approved the final manuscript.

EGEA cooperative group

Coordination: F Kauffmann; F Demenais (genetics); I Pin (clinical aspects). Respiratory epidemiology: Inserm U 700, Paris M Korobaeff (Egea1), F Neukirch (Egea1); Inserm U 707, Paris: I Annesi-Maesano; Inserm CESP/U 1018, Villejuif: F Kauffmann, N Le Moual, R Nadif, MP Oryszczyn; Inserm U 823, Grenoble: V Siroux Genetics: Inserm U 393, Paris: J Feingold; Inserm U 946, Paris: E Bouzigon, F Demenais, MH Dizier; CNG, Evry: I Gut, M Lathrop. Clinical centers: Grenoble: I Pin, C Pison; Lyon: D Ecochard (Egea1), F Gormand, Y Pacheco; Marseille: D Charpin (Egea1), D Vervloet; Montpellier: J Bousquet; Paris Cochin: A Lockhart (Egea1), R Matran (now in Lille); Paris Necker: E Paty, P Scheinmann; Paris-Trousseau: A Grimfeld, J Just. Data and quality management: Inserm ex-U155 (Egea1), Paris: J Hochez; Inserm CESP/ U 1018, Villejuif: N Le Moual, Inserm ex-U780, Villejuif: C Ravault; Inserm exU794, Evry: N Chateigner; Grenoble: J Ferran.

\section{Competing interests}

The authors declare that they have no competing interests.

Received: 25 January 2012 Accepted: 23 March 2012 Published: 23 March 2012

\section{References}

1. Colsoul B, Nilius B, Vennekens R: On the putative role of transient receptor potential cation channels in asthma. Clin Exp Allergy 2009, 39:1456-1466

2. Valverde MA, Cantero-Recasens G, Garcia-Elias A, Jung C, Carreras A, Vicente R: Ion channels and asthma. J Biol Chem 2011, 286:32877-32882.

3. Groneberg DA, Niimi A, Dinh QT, Cosio B, Hew M, Fischer A, Chung KF: Increased expression of transient receptor potential vanilloid-1 in airway nerves of chronic cough. Am J Respir Crit Care Med 2004, 170:1276-1280.

4. Mitchell JE, Campbell AP, New NE, Sadofsky LR, Kastelik JA, Mulrennan SA, Compton SJ, Morice AH: Expression and characterization of the intracellular vanilloid receptor (TRPV1) in bronchi from patients with chronic cough. Exp Lung Res 2005, 31:295-306.

5. Cantero-Recasens G, Gonzalez JR, Fandos C, Duran E, Smit LA, Kauffmann F, Antó JM, Valverde MA: Loss-of-function of transient receptor potential vanilloid 1 (TRPV1) genetic variant is associated with lower risk of active childhood asthma. J Biol Chem 2010, 285:27532-27535.

6. Andre E, Campi B, Materazzi S, Trevisani M, Amadesi S, Massi D, Creminon C, Vaksman N, Nassini R, Civelli M, Baraldi PG, Poole DP Bunnett NW, Geppetti P, Patacchini R: Cigarette smoke-induced neurogenic inflammation is mediated by alpha, beta-unsaturated aldehydes and the TRPA1 receptor in rodents. J Clin Invest 2008, 118:2574-2582.

7. Trevisani M, Siemens J, Materazzi S, Bautista DM, Nassini R, Campi B, Imamachi N, Andre E, Patacchini R, Cottrell GS, Gatti R, Basbaum Al, Bunnett NW, Julius D, Geppetti P: 4-Hydroxynonenal, an endogenous aldehyde, causes pain and neurogenic inflammation through activation of the irritant receptor TRPA1. Proc Natl Acad Sci USA 2007, 104:13519-13524.

8. Birrell MA, Belvisi MG, Grace M, Sadofsky L, Faruqi S, Hele DJ, Maher SA, Freund-Michel V, Morice AH: TRPA1 Agonists Evoke Coughing in Guineapig and Human Volunteers. Am J Respir Crit Care Med 2009, 180:1042-1047.

9. Laude EA, Higgins KS, Morice AH: A comparative study of the effects of citric acid, capsaicin and resiniferatoxin on the cough challenge in guinea-pig and man. Pulm Pharmacol 1993, 6:171-175

10. Caceres Al, Brackmann M, Elia MD, Bessac BF, del Camino D, D'Amours M, Witek JS, Fanger CM, Chong JA, Hayward NJ, Homer RJ, Cohn L, Huang X, Moran MM, Jordt SE: A sensory neuronal ion channel essential for airway inflammation and hyperreactivity in asthma. Proc Natl Acad Sci USA 2009, 106:9099-9104.

11. Kichko TI, Reeh PW: TRPV1 controls acid- and heat-induced calcitonin gene-related peptide release and sensitization by bradykinin in the isolated mouse trachea. Eur J Neurosci 2009, 29:1896-1904.
12. Andre E, Gatti R, Trevisani M, Preti D, Baraldi PG, Patacchini R, Geppetti P: Transient receptor potential ankyrin receptor 1 is a novel target for protussive agents. Br J Pharmacol 2009, 158:1621-1628.

13. Moran MM, McAlexander MA, Bíró T: Szallasi: Transient receptor potential channels as therapeutic targets. Nat Rev Drug Discov 2011, 10:601-620.

14. Alvarez DF, King JA, Weber D, Addison E, Liedtke W, Townsley MI: Transient receptor potential vanilloid 4-mediated disruption of the alveolar septal barrier: a novel mechanism of acute lung injury. Circ Res 2006, 99:988-995.

15. Hamanaka K, Jian MY, Weber DS, Alvarez DF, Townsley Ml, Al-Mehdi AB, King JA, Liedtke W, Parker JC: TRPV4 initiates the acute calciumdependent permeability increase during ventilator-induced lung injury in isolated mouse lungs. Am J Physiol 2007, 293:L923-L932.

16. Jia Y, Wang X, Varty L, Rizzo CA, Yang R, Correll CC, Phelps PT, Egan RW, Hey JA: Functional TRPV4 channels are expressed in human airway smooth muscle cells. Am J Physiol 2004, 287:L272-L278.

17. Lorenzo IM, Liedtke W, Sanderson MJ, Valverde MA: TRPV4 channel participates in receptor-operated calcium entry and ciliary beat frequency regulation in mouse airway epithelial cells. Proc Natl Acad SCi USA 2008, 105:12611-12616.

18. Vazquez $E$, Nobles $M$, Valverde MA: Defective regulatory volume decrease in human cystic fibrosis tracheal cells because of altered regulation of intermediate conductance $\mathrm{Ca}^{2+}$-dependent potassium channels. Proc Natl Acad Sci USA 2001, 98:5329-5334.

19. Arniges M, Vazquez E, Fernandez-Fernandez JM, Valverde MA: Swellingactivated $\mathrm{Ca}^{2+}$ entry via TRPV4 channel is defective in cystic fibrosis airway epithelia. J Biol Chem 2004, 279:54062-54068.

20. Zhu G, Gulsvik A, Bakke P, Ghatta S, Anderson W, Lomas DA, Silverman EK, Pillai SG: Association of TRPV4 gene polymorphisms with chronic obstructive pulmonary disease. Hum Mol Genet 2009, 18:2053-2062.

21. Brooks SM: Irritant-induced chronic cough: irritant-induced TRPpathy. Lung 2008, 186(Suppl 1):S88-S93.

22. Medina-Ramón M, Zock JP, Kogevinas M, Sunyer J, Antó JM: Asthma symptoms in women employed in domestic cleaning: a community based study. Thorax 2003, 58:950-954.

23. Medina-Ramón M, Zock JP, Kogevinas M, Sunyer J, Torralba Y, Borrell A, Burgos F, Antó JM: Asthma, chronic bronchitis, and exposure to irritant agents in occupational domestic cleaning: a nested case-control study. Occup Environ Med 2005, 62:598-606.

24. Le Moual N, Kennedy SM, Kauffmann F: Occupational exposures and asthma in 14,000 adults from the general population. Am J Epidemiol 2004, 160:1108-1116.

25. Kauffmann F, Dizier MH, Pin I, Paty E, Gormand F, Vervloet D, Bousquet J, Neukirch F, Annesi I, Oryszczyn MP, Lathrop M, Demenais F, Lockhart A, Feingold J: Epidemiological study of the genetics and environment of asthma, bronchial hyperresponsiveness, and atopy: phenotype issues. Am J Respir Crit Care Med 1997, 156:S123-S129.

26. Smit LA, Siroux V, Bouzigon E, Oryszczyn MP, Lathrop M, Demenais F, Kauffmann F: CD14 and toll-like receptor gene polymorphisms, country living, and asthma in adults. Am J Respir Crit Care Med 2009, 179:363-368.

27. European Community Respiratory Health Survey II Steering Committee: The European Community Respiratory Health Survey II. Eur Respir J 2002, 20:1071-1079.

28. Moffatt MF, Gut IG, Demenais F, Strachan DP, Bouzigon E, Heath S, von Mutius E, Farrall M, Lathrop M: Cookson WO for the GABRIEL Consortium: A large-scale, consortium-based genomewide association study of asthma. N Engl J Med 2010, 363:1211-1221.

29. Janson C, Chinn S, Jarvis D, Burney P: Determinants of cough in young adults participating in the European Community Respiratory Health Survey. Eur Respir J 2001, 18:647-654.

30. Siroux V, Pin I, Oryszczyn MP, Le Moual N, Kauffmann F: Relationships of active smoking to asthma and asthma severity in the EGEA study. Epidemiological study on the Genetics and Environment of Asthma. Eur Respir J 2000, 15:470-477.

31. Matheson MC, Benke G, Raven J, Sim MR, Kromhout H, Vermeulen R, Johns DP, Walters EH, Abramson MJ: Biological dust exposure in the workplace is a risk factor for chronic obstructive pulmonary disease. Thorax 2005, 60:645-651.

32. Smit LAM, Le Moual N, Antó JM, Bouzigon E, Kromhout H, Pin I, Vermeulen R, Demenais F, Kauffmann F: Occupational exposures increase 
the risk of cough in asthmatic adults in interaction with TRPV1 polymorphisms [abstract]. Eur Respir J 2009, 34:46s.

33. Benjamini $Y$, Hochberg Y: Controlling the False Discovery Rate: A Practical and Powerful Approach to Multiple Testing. J R Statist Soc B 1995, 57:289-300.

34. Gonzalez JR, Armengol L, Sole X, Guino E, Mercader JM, Estivill X, Moreno V: SNPassoc: an $\mathrm{R}$ package to perform whole genome association studies. Bioinformatics 2007, 23:644-645.

35. Lake SL, Lyon H, Tantisira K, Silverman EK, Weiss ST, Laird NM, Schaid DJ: Estimation and tests of haplotype-environment interaction when linkage phase is ambiguous. Hum Hered 2003, 55:56-65.

36. French CL, Irwin RS, Curley FJ, Krikorian CJ: Impact of chronic cough on quality of life. Arch Intern Med 1998, 158:1657-1661.

37. Chung KF: Effective antitussives for the chronic cough patient: an unmet need. Pulm Pharmacol Ther 2007, 20:438-445.

38. Sunyer J, Basagana X, Burney P, Antó JM: International assessment of the internal consistency of respiratory symptoms. European Community Respiratory Health Study (ECRHS). Am J Respir Crit Care Med 2000, 162:930-935.

39. Chung KF: Chronic 'cough hypersensitivity syndrome': A more precise label for chronic cough. Pulm Pharmacol Ther 2011, 24:267-271.

40. Morice AH, Faruqi S, Wright CE, Thompson R, Bland JM: Cough hypersensitivity syndrome: a distinct clinical entity. Lung 2011, 189:73-79.

41. Siroux V, Boudier A, Bousquet J, Bresson JL, Cracowski JL, Ferran J, Gormand F, Just J, Le Moual N, Morange S, Nadif R, Oryszczyn MP, Pison C, Scheinmann P, Varraso R, Vervloet D, Pin I, Kauffmann F: Phenotypic determinants of uncontrolled asthma. J Allergy Clin Immunol 2009, 124:681-687.

42. Kastelik JA, Thompson RH, Aziz I, Ojoo JC, Redington AE, Morice AH: Sexrelated differences in cough reflex sensitivity in patients with chronic cough. Am J Respir Crit Care Med 2002, 166:961-964.

43. Fujimura M, Kasahara K, Kamio Y, Naruse M, Hashimoto T, Matsuda T: Female gender as a determinant of cough threshold to inhaled capsaicin. Eur Respir J 1996, 9:1624-1626.

doi:10.1186/1465-9921-13-26

Cite this article as: Smit et al: Transient receptor potential genes, smoking, occupational exposures and cough in adults. Respiratory Research 2012 13:26.

\section{Submit your next manuscript to BioMed Central and take full advantage of:}

- Convenient online submission

- Thorough peer review

- No space constraints or color figure charges

- Immediate publication on acceptance

- Inclusion in PubMed, CAS, Scopus and Google Scholar

- Research which is freely available for redistribution

Submit your manuscript at www.biomedcentral.com/submit 